\title{
PERHITUNGAN KINERJA SIMPANG BERSINYAL MENGGUNAKAN METODE MKJI 1997 DAN PERANGKAT LUNAK PTV VISTRO (Studi Kasus Simpang Empat Ngemplak dan Simpang Tiga Gilingan Kota Surakarta)
}

\author{
Calculation of Signalized Intersection Performance using IHCM 1997 Method and Application PTV VISTRO Software \\ (Ngemplak and Gilingan Intersections Case Study)
}

Elsafan Gelar Geladi'1,Budi Yulianto², Edy Purwanto ${ }^{3}$

\begin{abstract}
ABSTRAK
Jalan Ahmad Yani adalah salah satu jalan utama yang melayani pergerakan transportasi Kota Surakarta. Merupakan jalan arteri sehingga banyak kendaraan melewati jalan ini. Volume lalu lintas yang relatif tinggi di jalan Ahmad Yani mempengaruhi kinerja simpang di sepanjang jalan ini. Tujuan penelitian ini adalah untuk menganalisis kinerja simpang bersinyal di sepanjang jalan Ahmad Yani dengan menggunakan metode MKJI 1997 dan perangkat lunak PTV VISTRO. Metode MKJI 1997 adalah metode pemodelan lalu lintas berdasarkan kondisi empiris lalu lintas Indonesia. PTV VISTRO adalah perangkat lunak pemodelan lalu lintas berdasarkan kondisi empiris lalu lintas Amerika Serikat. Analisis hasil kinerja simpang bersinyal menggunakan kedua pendekatan dibandingkan dengan data lapangan. Pemodelan dilakukan untuk melihat kemiripan hasil kinerja lalu lintas antara pemodelan dengan data lapangan. Secara umum perangkat lunak PTV VISTRO menghasilkan panjang antrian kendaraan yang lebih dekat dengan data lapangan dari pada metode MKJI 1997. Perangkat lunak PTV VISTRO cenderung menghasilkan tingkat kejenuhan yang lebih rendah, tundaan dan Tingkat Layanan daripada metode MKJI 1997.
\end{abstract}

Kata kunci : simpang bersinyal, kinerja simpang, MKJI 1997, PTV VISTRO

\begin{abstract}
Ahmad Yani road is one of the main city road serving the transportation movement of Surakarta City. It's on an arterial road so that many vehicles pass through this road. Relatively high traffic volume in Ahmad Yani road affects the signalized intersections performance along this road. The aim of this study is to analyze the signalized intersections performance along Ahmad Yani road by using MKJI 1997 method and PTV VISTRO software. The MKJI 1997 method is traffic modelling method based on empirical Indonesian traffic conditions. PTV VISTRO is traffic modelling software based on empirical United States America traffic conditions. Analysis of the signalized intersections performance results using both approaches is compared with the field data. Calibration and validation of models is carried out to see the similarity of traffic performance results between models with field data. In general PTV VISTRO software produces vebicle queue length closer to field data than MKJI 1997 method. PTV VISTRO software tends to produce lower degree of saturation, vehicle delay and Level of Service than MKJI 1997 method.
\end{abstract}

Keywords $\quad$ : signalized intersection, intersection's performance, MKJI 1997, PTV VISTRO

\section{PENDAHULUAN}

Persimpangan merupakan elemen kritis pada jalan raya yang menjadi salah satu titik rawan kemacetan. Tingkat kemacetan pada persimpangan dipengaruhi oleh kapasitas jalan. Jenis simpang yang digunakan untuk meningkatkan arus lalu lintas yaitu simpang bersinyal. Untuk menghitung kapasitas jalan, beberapa negara mengeluarkan cara atau perumusan yang didasari dari hasil riset di negara tersebut yang diperbaharui dari waktu ke waktu sesuai dengan kemajuan teknologi dan perkembangan lingkungannya.

Metode yang digunakan untuk menganalisis kinerja simpang di Indonesia adalah Manual Kapasitas Jalan Raya Indonesia (MKJI, 1997). Metode ini dilihat berdasarkan data empiris kondisi lalu lintas di Indonesia. Perkembangan perangkat lunak sangat pesat sebagai bagian upaya penyelesaian masalah transportasi. Perangkat lunak yang sedang berkembang adalah PTV VISTRO (PTV AG, 2015). PTV VISTRO merupakan perangkat lunak yang digunakan untuk menganalisis kinerja simpang berdasarkan metode HCM 2010. Metode ini merupakan hasil empiris dari kondisi lalu lintas di Amerika Serikat. 
Simpang bersinyal yang akan diobservasi adalah Simpang Empat Ngemplak dan Simpang Tiga Gilingan. Kedua simpang tersebut dipilih oleh peneliti karena berada di Jalan Ahmad Yani, yang merupakan jalur antar provinsi dan memiliki arus yang padat. Kinerja kedua simpang bersinyal tersebut akan dianalisis menggunakan metode MKJI 1997 dan perangkat lunak PTV VISTRO. Skenario tertentu pada analisis kedua metode tersebut diperlukan agar hasil yang didapat mendekati data di lapangan. Skenario yang dimaksud adalah analisis dengan menggunakan model dasar (Base Model) metode tersebut, nilai konstanta pada perhitungan arus jenuh dasar (Widodo, 1997), dan Ekivalensi Mobil Penumpang (EMP) Sepeda Motor (MC) yang dimodifikasi (Gati, 2009). Sedangkan data di lapangan yang diukur adalah panjang antrian. Kemudian hasil analisis kedua metode tersebut yaitu derajat kejenuhan, tundaan dan panjang antrian dibandingkan satu sama lain setelah data panjang antrian hasil analisis dibandingkan dengan data panjang antrian di lapangan.

\section{LANDASAN TEORI}

\section{Lokasi dan Waktu Penelitian}

Penelitian ini dilaksanakan di Simpang Empat Ngemplak dan Simpang Tiga Gilingan. Survai dilakukan pada tanggal 13 September 2017. Pengambilan data dilakukan oleh surveyor - surveyor pada pagi hari dan sore hari, yaitu pada pukul $06.00-08.00$ WIB dan $16.00-18.00$ WIB.

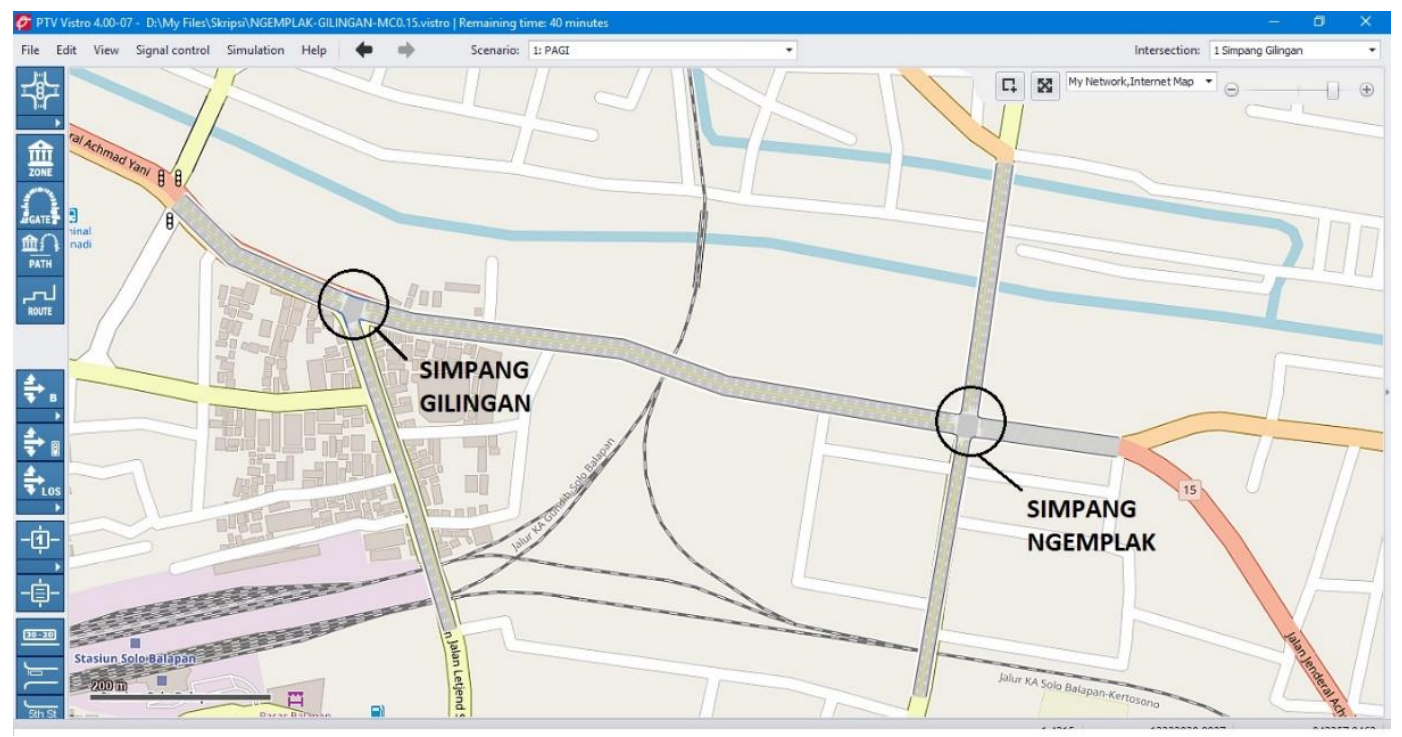

Gambar 1. Lokasi Penelitian

\section{Prosedur Perhitungan}

Prosedur perhitungan kinerja simpang bersinyal dengan metode MKJI 1997 dan perangkat lunak PTV VISTRO dibagi menjadi 3 bagian yaitu konfigurasi dasar metode tersebut (Base Model), nilai Konstanta pada perhitungan Arus Jenuh Dasar (Widodo, 1997) dan Ekivalensi Mobil Penumpang (EMP) Sepeda Motor (MC) yang dimodifikasi (Gati, 2009). Perbedaan skenario perhitungan antara metode MKJI 1997 dan PTV VISTRO dapat dilihat pada Tabel 1.

Tabel 1. Perbedaan Skenario Antara Metode MKJI 1997 dan PTV VISTRO

\begin{tabular}{|c|c|c|c|}
\hline No. & Skenario & MKJI 1997 & PTV VISTRO \\
\hline \multirow{2}{*}{1} & \multirow{2}{*}{ Base Model } & - EMP MC $=0,2$ & - $\mathrm{EMP} \mathrm{MC}=0,2$ \\
\hline & & $-\mathrm{S}_{0}=$ Lebar Pendekat x 600 & $-\mathrm{S}_{0}=1900$ \\
\hline \multirow{2}{*}{2} & \multirow{2}{*}{ Widodo (1997) } & $-\mathrm{EMP} \mathrm{MC}=0,2$ & - EMP MC $=0,2$ \\
\hline & & $-\mathrm{S}_{0}=$ Lebar Pendekat x 775 & $-\mathrm{S}_{0}=$ Lebar Lajur $\mathrm{x} 775$ \\
\hline \multirow{2}{*}{3} & \multirow{2}{*}{ Gati (2009) } & $-\mathrm{EMP}$ MC $=0,15$ & - EMP MC = 0,15 \\
\hline & & $-\mathrm{S}_{0}=$ Lebar Pendekat x 775 & $-\mathrm{S}_{0}=$ Lebar Lajur x 775 \\
\hline
\end{tabular}




\section{Perbandingan}

Panjang antrian kendaraan yang didapatkandari semua skenario metode MKJI 1997 dan perangkat lunak PTV VISTRO dibandingkan dengan data lapangan. Hasil kinerja simpang bersinyal dari metode MKJI 1997 dan skenario perangkat lunak PTV VISTRO dengan panjang antrian kendaraan yang paling mendekati data lapangan akan dibandingkan. Yang akan dibandingkan adalah derajat kejenuhan, panjang antrian kendaraan, tundaan dan tingkat layanan simpang atau LoS.

\section{HASIL PENELITIAN DAN PEMBAHASAN}

\section{Perbandingan Analisis Metode MKJI 1997 dengan Data Lapangan}

Perbandingan hasil metode MKJI 1997 dan data lapangan untuk kondisi jam puncak pagi dan siang hari dapat dilihat pada Tabel 2 dan 3. Hasil perhitungan menunjukkan bahwa Base Model menghasilkan nilai saturation flow yang relatif besar. Panjang antrian kendaraan yang dihasilkan sangat panjang dan tidak sesuai dengan kenyataan di lapangan. Fenomena ini menunjukkan bahwa metode MKJI 1997 dengan nilai default menghasilkan ukuran lalu lintas kinerja yang tidak sesuai dengan kondisi lapangan. Skenario-skenario tersebut menunjukkan bahwa perubahan nilai konstanta saturation flow dari 600 menjadi 775 masih menghasilkan nilai panjang antrian kendaraan yang relatif besar dibandingkan dengan data lapangan. Dengan mengubah nilai EMP untuk sepeda motor dari 0,2 menjadi 0,15 maka nilai panjang antrian kendaraan yang dihasilkan pada skenario Gati (2009) menjadi lebih dekat dengan data lapangan. Hasil uji t menunjukkan nilai $\mathrm{P}($ two-tailed $)>$ 0,025, itu berarti perbedaan skenario Gati (2009) dengan data lapangan tidak signifikan dalam kondisi jam puncak pagi dan sore (lihat Tabel 4)

Tabel 2. Rekaptulasi Kinerja Simpang Empat Ngemplak dengan MKJI 1997

\section{PARAMETER KINERJA SIMPANG BERSINYAL}

\begin{tabular}{|c|c|c|c|c|c|c|c|c|c|c|c|}
\hline \multirow{3}{*}{ Waktu } & \multirow{3}{*}{ Pendekat } & \multirow{2}{*}{\multicolumn{3}{|c|}{ DS (Derajat Kejenuhan) }} & \multirow{2}{*}{\multicolumn{4}{|c|}{ QL (Panjang Antrian) (meter) }} & \multirow{2}{*}{\multicolumn{3}{|c|}{$\mathrm{D}$ (Tundaan) (det/smp) }} \\
\hline & & & & & & & & & & & \\
\hline & & $\begin{array}{l}\text { MKJI } \\
(1997)\end{array}$ & $\begin{array}{c}\text { Widodo } \\
\text { (1997) }\end{array}$ & $\begin{array}{c}\text { Gati } \\
(2009)\end{array}$ & $\begin{array}{l}\text { MKJI } \\
(1997)\end{array}$ & $\begin{array}{c}\text { Widodo } \\
\text { (1997) }\end{array}$ & $\begin{array}{c}\text { Gati } \\
(2009)\end{array}$ & Lapangan & $\begin{array}{l}\text { MKJI } \\
\text { (1997) }\end{array}$ & $\begin{array}{c}\text { Widodo } \\
\text { (1997) }\end{array}$ & $\begin{array}{l}\text { Gati } \\
\text { (2009) }\end{array}$ \\
\hline \multirow{4}{*}{$\begin{array}{c}06.30- \\
07.30\end{array}$} & Barat & 1,57 & 1,21 & 1,07 & 1191 & 690 & 363 & 101 & 1109,61 & 462,06 & 207,5 \\
\hline & Timur & 1,20 & 0,93 & 0,82 & 464 & 164 & 133 & 112 & 433,88 & 73,45 & 60,71 \\
\hline & Utara & 1,45 & 1,12 & 0,95 & 954 & 483 & 205 & 143 & 900,21 & 308,84 & 92,25 \\
\hline & Selatan & 1,01 & 0,79 & 0,66 & 194 & 123 & 100 & 79 & 162,36 & 66,62 & 60,03 \\
\hline \multirow{4}{*}{$\begin{array}{l}16.00- \\
17.00\end{array}$} & Barat & 1,38 & 1,07 & 0,95 & 821 & 352 & 191 & 152 & 760,09 & 203,45 & 81,82 \\
\hline & Timur & 1,34 & 1,03 & 0,93 & 702 & 272 & 167 & 180 & 687,92 & 155,05 & 74,19 \\
\hline & Utara & 1,10 & 0,85 & 0,72 & 349 & 161 & 129 & 99 & 281,96 & 69,58 & 60,02 \\
\hline & Selatan & 1,35 & 1,05 & 0,89 & 650 & 282 & 151 & 174 & 728,77 & 195,44 & 80,64 \\
\hline
\end{tabular}

Tabel 3. Rekaptulasi Kinerja Simpang Tiga Gilingan dengan MKJI 1997

PARAMETER KINERJA SIMPANG BERSINYAL

\begin{tabular}{|c|c|c|c|c|c|c|c|c|c|c|c|}
\hline \multirow{2}{*}{ Waktu } & \multirow{2}{*}{ Pendekat } & \multicolumn{3}{|c|}{ DS (Derajat Kejenuhan) } & \multicolumn{4}{|c|}{ QL (Panjang Antrian) (meter) } & \multicolumn{3}{|c|}{ D (Tundaan) (det/smp) } \\
\hline & & $\begin{array}{l}\text { MKJI } \\
\text { (1997) }\end{array}$ & $\begin{array}{c}\text { Widodo } \\
\text { (1997) }\end{array}$ & $\begin{array}{l}\text { Gati } \\
(2009)\end{array}$ & $\begin{array}{l}\text { MKJI } \\
\text { (1997) }\end{array}$ & $\begin{array}{c}\text { Widodo } \\
\text { (1997) }\end{array}$ & $\begin{array}{l}\text { Gati } \\
(2009)\end{array}$ & Lapangan & $\begin{array}{l}\text { MKJI } \\
\text { (1997) }\end{array}$ & $\begin{array}{c}\text { Widodo } \\
(1997)\end{array}$ & $\begin{array}{l}\text { Gati } \\
\text { (2009) }\end{array}$ \\
\hline \multirow{4}{*}{$\begin{array}{c}06.30- \\
07.30\end{array}$} & Barat ST-1 & 1,06 & 0,82 & 0,72 & 273 & 106 & 88 & 65 & 171,57 & 34,20 & 30,72 \\
\hline & Barat ST-2 & 0,99 & 0,76 & 0,68 & 195 & 121 & 106 & 65 & 114,44 & 47,77 & 44,54 \\
\hline & Timur & 1,17 & 0,90 & 0,80 & 509 & 135 & 107 & 67 & 364,04 & 42,40 & 32,64 \\
\hline & Selatan & 0,61 & 0,47 & 0,41 & 61 & 57 & 50 & 30 & 32,03 & 28,45 & 27,30 \\
\hline \multirow{4}{*}{$\begin{array}{c}16.00- \\
17.00\end{array}$} & Barat ST-1 & 0,76 & 0,59 & 0,52 & 75 & 69 & 60 & 53 & 32,56 & 28,24 & 27,30 \\
\hline & Barat ST-2 & 0,79 & 0,61 & 0,55 & 105 & 96 & 87 & 70 & 51,61 & 42,86 & 41,81 \\
\hline & Timur & 0,98 & 0,76 & 0,69 & 157 & 99 & 88 & 85 & 78,61 & 30,62 & 28,38 \\
\hline & Selatan & 0,56 & 0,44 & 0,37 & 55 & 52 & 46 & 30 & 30,42 & 27,61 & 26,59 \\
\hline
\end{tabular}


Tabel 4. Hasil Uji T Antara Metode MKJI 1997 dengan Data Lapangan

\begin{tabular}{ccccc}
\hline \multirow{2}{*}{ Parameter } & \multicolumn{2}{c}{ Pagi } & \multicolumn{2}{c}{ Sore } \\
\cline { 2 - 5 } & $\begin{array}{c}\text { MKJI 1997 } \\
(\text { Gati, 2009) }\end{array}$ & $\begin{array}{c}\text { Data } \\
\text { Lapangan }\end{array}$ & $\begin{array}{c}\text { MKJI 1997 } \\
(\text { Gati, 2009) }\end{array}$ & $\begin{array}{c}\text { Data } \\
\text { Lapangan }\end{array}$ \\
\hline Rata-rata & 143,96 & 82,60 & 114,87 & 105,38 \\
\hline Varian & 9804,86 & 1210,08 & 2738,63 & 3235,49 \\
\hline Derajat Kebebasan & \multicolumn{2}{c}{7} & 7 \\
\hline $\mathrm{T}_{\text {hitung }}$ & 2,10 & 1,30 \\
\hline Nilai P (one-tailed) & 0,04 & 0,12 \\
\hline $\mathrm{T}_{\text {tabel }}$ (one-tailed) & 1,89 & 1,89 \\
\hline Nilai P (two-tailed) & 0,07 & 0,23 \\
\hline $\mathrm{Tt}_{\text {abel }}$ (two-tailed) & 2,36 & 2,36 \\
\hline
\end{tabular}

\section{Perbandingan Analisis Perangkat PTV VISTRO dengan Data Lapangan}

Perbandingan hasil perangkat lunak PTV VISTRO dan data lapangan untuk kondisi jam puncak pagi dan siang hari dapat dilihat pada Tabel 5 dan 6. Hasil perhitungan menunjukkan bahwa Base Model menghasilkan nilai saturation flow yang relatif besar, begitu pula dengan panjang antrian. Hasil perangkat lunak PTV VISTRO pada umumnya hampir sama dengan metode MKJI 1997. Tingkat kejenuhan yang lebih besar cenderung menghasilkan perbedaan persentase yang lebih besar dalam antrian panjang kendaraan antara hasil skenario dengan data lapangan. Seperti dalam kasus metode MKJI 1997, skenario Gati (2009) menunjukkan bahwa dengan mengubah EMP untuk sepeda motor dari 0,2 menjadi 0,15 menghasilkan nilai panjang antrian kendaraan yang lebih mendekati dengan data di lapangan. Hasil uji t menunjukkan perbedaan antara hasil skenario Gati (2009) dengan data lapangan tidak signifikan dalam kondisi jam puncak pagi dan puncak sore (lihat Tabel 7).

Tabel 5. Rekapitulasi Kinerja Simpang Empat Ngemplak dengan PTV VISTRO

\begin{tabular}{|c|c|c|c|c|c|c|c|c|c|c|c|}
\hline \multirow[b]{3}{*}{ Waktu } & \multirow[b]{3}{*}{ Pendekat } & \multicolumn{10}{|c|}{ PARAMETER KINERJA SIMPANG BERSINYAL } \\
\hline & & \multicolumn{3}{|c|}{ DS (Derajat Kejenuhan) } & \multicolumn{4}{|c|}{ QL (Panjang Antrian) (meter) } & \multicolumn{3}{|c|}{$\mathrm{D}$ (Tundaan) (det/smp) } \\
\hline & & $\begin{array}{c}\text { PTV } \\
\text { VISTRO }\end{array}$ & Widodo & Gati & $\begin{array}{c}\text { PTV } \\
\text { VISTRO }\end{array}$ & Widodo & Gati & Lapangan & $\begin{array}{c}\text { PTV } \\
\text { VISTRO }\end{array}$ & Widodo & Gati \\
\hline \multirow{4}{*}{$\begin{array}{c}06.30- \\
07.30\end{array}$} & Barat & 1,12 & 0,85 & 0,75 & 422 & 191 & 160 & 101 & 312,55 & 70,49 & 60,23 \\
\hline & Timur & 0,89 & 0,58 & 0,52 & 171 & 135 & 120 & 112 & 84,54 & 50,96 & 49,06 \\
\hline & Utara & 1,15 & 1,25 & 1,06 & 440 & 581 & 285 & 143 & 353,43 & 529,05 & 225,86 \\
\hline & Selatan & 0,76 & 0,83 & 0,71 & 113 & 121 & 96 & 79 & 73,12 & 85,88 & 68,92 \\
\hline \multirow{4}{*}{$\begin{array}{c}16.00- \\
17.00\end{array}$} & Barat & 1,05 & 0,79 & 0,71 & 274 & 164 & 143 & 152 & 215,29 & 66,81 & 60,02 \\
\hline & Timur & 1,05 & 0,69 & 0,62 & 304 & 157 & 140 & 180 & 209,11 & 56,54 & 53,68 \\
\hline & Utara & 0,93 & 1,01 & 0,86 & 171 & 220 & 135 & 99 & 106,71 & 172,32 & 86,99 \\
\hline & Selatan & 1,10 & 1,19 & 1,02 & 290 & 395 & 194 & 174 & 289,35 & 448,70 & 197,64 \\
\hline
\end{tabular}


Tabel 6. Rekapitulasi Kinerja Simpang Tiga Gilingan dengan PTV VISTRO

PARAMETER KINERJA SIMPANG BERSINYAL

\begin{tabular}{|c|c|c|c|c|c|c|c|c|c|c|c|}
\hline \multirow{2}{*}{ Waktu } & \multirow{2}{*}{ Pendekat } & \multicolumn{3}{|c|}{ DS (Derajat Kejenuhan) } & \multicolumn{4}{|c|}{ QL (Panjang Antrian) (meter) } & \multicolumn{3}{|c|}{ D (Tundaan) (det/smp) } \\
\hline & & $\begin{array}{c}\text { PTV } \\
\text { VISTRO }\end{array}$ & Widodo & Gati & $\begin{array}{c}\text { PTV } \\
\text { VISTRO }\end{array}$ & Widodo & Gati & Lapangan & $\begin{array}{c}\text { PTV } \\
\text { VISTRO }\end{array}$ & Widodo & Gati \\
\hline \multirow{4}{*}{$\begin{array}{c}06.30- \\
07.30\end{array}$} & Barat ST-1 & 0,98 & 0,80 & 0,71 & 259 & 141 & 114 & 65 & 53,71 & 15,62 & 12,49 \\
\hline & Barat ST-2 & 0,80 & 0,49 & 0,42 & 83 & 70 & 60 & 65 & 33,59 & 24,40 & 23,60 \\
\hline & Timur & 0,95 & 0,46 & 0,41 & 132 & 86 & 77 & 67 & 50,29 & 21,77 & 21,24 \\
\hline & Selatan & 0,78 & 0,54 & 0,47 & 81 & 67 & 58 & 30 & 43,62 & 29,66 & 28,06 \\
\hline \multirow{4}{*}{$\begin{array}{c}16.00- \\
17.00\end{array}$} & Barat ST-1 & 0,79 & 0,65 & 0,58 & 119 & 97 & 83 & 53 & 16,40 & 10,91 & 9,74 \\
\hline & Barat ST-2 & 0,50 & 0,31 & 0,27 & 48 & 43 & 37 & 70 & 25,35 & 22,53 & 22,17 \\
\hline & Timur & 0,79 & 0,39 & 0,36 & 90 & 73 & 67 & 85 & 30,47 & 21,02 & 20,71 \\
\hline & Selatan & 0,70 & 0,49 & 0,42 & 69 & 60 & 51 & 30 & 37,79 & 28,50 & 27,25 \\
\hline
\end{tabular}

Tabel 7. Hasil Uji T Antara PTV VISTRO dengan Data Lapangan

\begin{tabular}{|c|c|c|c|c|}
\hline \multirow[b]{2}{*}{ Parameter } & \multicolumn{2}{|c|}{ Pagi } & \multicolumn{2}{|c|}{ Sore } \\
\hline & $\begin{array}{c}\text { PTV } \\
\text { VISTRO } \\
(\text { Gati, 2009) }\end{array}$ & $\begin{array}{c}\text { Data } \\
\text { Lapangan }\end{array}$ & $\begin{array}{c}\text { PTV } \\
\text { VISTRO } \\
\text { (Gati, 2009) }\end{array}$ & $\begin{array}{c}\text { Data } \\
\text { Lapangan }\end{array}$ \\
\hline Rata-rata & 121,28 & 82,60 & 106,27 & 105,38 \\
\hline Varian & 5517,18 & 1210,08 & 2985,24 & 3235,49 \\
\hline Derajat Kebebasan & \multicolumn{2}{|c|}{8} & \multicolumn{2}{|c|}{8} \\
\hline $\mathrm{T}_{\text {hitung }}$ & \multicolumn{2}{|c|}{2,33} & \multicolumn{2}{|c|}{0,09} \\
\hline Nilai P (one-tailed) & \multicolumn{2}{|c|}{0,03} & \multicolumn{2}{|c|}{0,47} \\
\hline $\mathrm{T}_{\text {tabel }}$ (one-tailed) & \multicolumn{2}{|c|}{1,89} & \multicolumn{2}{|c|}{1,89} \\
\hline Nilai P (two-tailed) & \multicolumn{2}{|c|}{0,05} & \multicolumn{2}{|c|}{0,93} \\
\hline $\mathrm{Tt}_{\text {abel }}$ (two-tailed) & \multicolumn{2}{|c|}{2,36} & \multicolumn{2}{|c|}{2,36} \\
\hline
\end{tabular}

\section{Perbandingan Kinerja Simpang Bersinyal Metode MKJI 1997 dengan PTV VISTRO}

Hasil kinerja simpang bersinyal dari metode MKJI 1997 dan skenario perangkat lunak PV VISTRO yang menghasilkan panjang antrian kendaraan yang paling dekat dengan data lapangan yaitu skenario Gati (2009) akan dibandingkan. Dalam hal ini yang dibandingkan adalah derajat kejenuhan, panjang antrian, tundaan dan tingkat layanan simpang. Tabel 8 dan 9 menunjukkan perbandingan metode MKJI 1997 dan hasil perangkat lunak PTV VISTRO untuk kondisi jam puncak pagi dan siang hari. Secara umum, perangkat lunak PTV VISTRO menghasilkan panjang antrian kendaraan lebih dekat ke data lapangan daripada metode MKJI 1997. Perangkat lunak PTV VISTRO cenderung menghasilkan derajat kejenuhan yang lebih rendah daripada Metode MKJI 1997. Ini menyebabkan nilai tundaan dan LOS simpang memiliki nilai yang rendah. 
Tabel 8. Perbandingan Kinerja Simpang Empat Ngemplak antara MKJI 1997 dengan PTV VISTRO PARAMETER KINERJA SIMPANG BERSINYAL

\begin{tabular}{|c|c|c|c|c|c|c|c|c|}
\hline \multirow{2}{*}{ Waktu } & \multirow{2}{*}{ Pendekat } & \multicolumn{2}{|c|}{ DS (Derajat Kejenuhan) } & \multicolumn{3}{|c|}{ QL (Panjang Antrian) (meter) } & \multicolumn{2}{|c|}{ D (Tundaan) (det/smp) } \\
\hline & & $\begin{array}{l}\text { MKJI } 1997 \\
\text { (Gati, 2009) }\end{array}$ & $\begin{array}{c}\text { PTV } \\
\text { VISTRO } \\
\text { (Gati, 2009) }\end{array}$ & $\begin{array}{l}\text { MKJI } 1997 \\
\text { (Gati, 2009) }\end{array}$ & $\begin{array}{c}\text { PTV } \\
\text { VISTRO } \\
(\text { Gati, 2009) }\end{array}$ & Lapangan & $\begin{array}{l}\text { MKJI } 1997 \\
\text { (Gati, 2009) }\end{array}$ & $\begin{array}{l}\text { PTV VISTRO } \\
\text { (Gati, 2009) }\end{array}$ \\
\hline \multirow{5}{*}{$\begin{array}{c}06.30- \\
07.30\end{array}$} & Utara & 1,07 & 0,75 & 363,3 & 160,5 & 101,0 & 207,54 & 60,23 \\
\hline & Barat & 0,82 & 0,52 & 133,0 & 120,0 & 112,0 & 60,71 & 49,06 \\
\hline & Selatan & 0,95 & 1,06 & 204,6 & 284,6 & 142,7 & 92,25 & 225,86 \\
\hline & Timur & 0,66 & 0,71 & 99,8 & 96,2 & 78,5 & 60,03 & 68,92 \\
\hline & Simpang & - & 0,69 & - & - & - & 109,56 & 93,25 \\
\hline \multirow{5}{*}{$\begin{array}{l}16.00- \\
17.00\end{array}$} & Utara & 0,95 & 0,71 & 190,9 & 142,7 & 152,5 & 81,82 & 60,02 \\
\hline & Barat & 0,93 & 0,62 & 166,6 & 139,6 & 180,0 & 74,19 & 53,68 \\
\hline & Selatan & 0,72 & 0,86 & 128,9 & 135,3 & 99,2 & 60,02 & 86,99 \\
\hline & Timur & 0,89 & 1,02 & 151,2 & 194,1 & 173,8 & 80,64 & 197,64 \\
\hline & Simpang & - & 0,68 & - & - & - & 70,63 & 82,87 \\
\hline
\end{tabular}

Tabel 9. Perbandingan Kinerja Simpang Tiga Gilingan antara MKJI 1997 dengan PTV VISTRO

\begin{tabular}{|c|c|c|c|c|c|c|c|c|}
\hline \multirow{3}{*}{ Waktu } & \multirow{3}{*}{ Pendekat } & \multicolumn{7}{|c|}{ PARAMETER KINERJA SIMPANG BERSINYAL } \\
\hline & & \multicolumn{2}{|c|}{ DS (Derajat Kejenuhan) } & \multicolumn{3}{|c|}{ QL (Panjang Antrian) (meter) } & \multicolumn{2}{|c|}{ D (Tundaan) (det/smp) } \\
\hline & & $\begin{array}{l}\text { MKJI } 1997 \\
\text { (Gati, 2009) }\end{array}$ & $\begin{array}{c}\text { PTV } \\
\text { VISTRO } \\
\text { (Gati, 2009) }\end{array}$ & $\begin{array}{l}\text { MKJI } 1997 \\
\text { (Gati, 2009) }\end{array}$ & $\begin{array}{c}\text { PTV } \\
\text { VISTRO } \\
\text { (Gati, 2009) }\end{array}$ & Lapangan & $\begin{array}{l}\text { MKJI } 1997 \\
\text { (Gati, 2009) }\end{array}$ & $\begin{array}{l}\text { PTV VISTRO } \\
\text { (Gati, 2009) }\end{array}$ \\
\hline \multirow{5}{*}{$\begin{array}{l}06.30- \\
07.30\end{array}$} & Barat ST-1 & 0,72 & 0,75 & 87,7 & 113,9 & 65,0 & 30,72 & 12,49 \\
\hline & Barat ST-2 & 0,68 & 0,52 & 106,2 & 60,5 & 65,0 & 44,54 & 23,60 \\
\hline & Timur & 0,80 & 1,06 & 106,8 & 77,0 & 66,7 & 32,64 & 21,24 \\
\hline & Selatan & 0,41 & 0,71 & 50,3 & 57,6 & 30,0 & 27,30 & 28,06 \\
\hline & Simpang & - & 0,56 & - & - & - & 27,70 & 19,37 \\
\hline \multirow{5}{*}{$\begin{array}{l}16.00- \\
17.00\end{array}$} & Barat ST-1 & 0,52 & 0,71 & 60,2 & 83,3 & 52,5 & 27,30 & 9,74 \\
\hline & Barat ST-2 & 0,55 & 0,62 & 87,2 & 37,3 & 69,6 & 41,81 & 22,17 \\
\hline & Timur & 0,69 & 0,86 & 87,6 & 67,4 & 85,5 & 28,38 & 20,71 \\
\hline & Selatan & 0,37 & 1,02 & 46,3 & 50,5 & 30,0 & 26,59 & 27,25 \\
\hline & Simpang & - & 0,47 & - & - & - & 23,39 & 17,78 \\
\hline
\end{tabular}

Analisis kinerja persimpangan menggunakan metode MKJI 1997 dan perangkat lunak PTV VISTRO menunjukkan perbedaan hasil karena beberapa faktor berikut:

1. Parameter saturation flow yang digunakan menggunakan rumus metode MKJI 1997. Ini mungkin tidak sesuai dengan pendekatan perangkat lunak PTV VISTRO. Hal ini karena analisis pergerakan lalu lintas metode MKJI 1997 didasarkan pada lebar per pendekat, sedangkan perangkat lunak PTV VISTRO didasarkan pada lebar per lajur.

2. Faktor penyesuaian yang digunakan dalam perhitungan saturation flow antara metode MKJI 1997 dan perangkat lunak PTV VISTRO berbeda.

3. Perhitungan waktu sinyal antara metode MKJI 1997 dan perangkat lunak PTV VISTRO berbeda. 


\section{KESIMPULAN}

Hasil analisis kinerja simpang bersinyal menunjukkan bahwa panjang antrian pada metode MKJI 1997 dan perangkat lunak PTV VISTRO berbeda dengan panjang antrian kendaraan berdasarkan data dilapangan. Dengan mengubah nilai base saturation flow dan EMP untuk sepeda motor, pemodelan menghasilkan panjang antrian kendaraan lebih mendekati data lapangan. Hasil uji t menunjukkan bahwa tidak ada perbedaan yang signifikan antara hasil pemodelan dan data di lapangan. Perangkat lunak PTV VISTRO cenderung menghasilkan derajat kejenuhan, tundaan dan LoS yang lebih rendah daripada metode MKJI 1997. Hasil yang didapat dari metode MKJI 1997 dan perangkat lunak PTV VISTRO berbeda karena perbedaan dalam hal analisis pergerakan lalu lintas jalan, faktor penyesuaian yang digunakan, saturation flow dan perhitungan waktu sinyal.

\section{DAFTAR PUSTAKA}

Anonim. 1997. Manual Kapasitas Jalan Indonesia (MKJI) 1997. Jakarta: Direktorat Jenderal Bina Marga Departemen Pekerjaan Umum RI.

Anonim 2. 2006. Peraturan Menteri Perbubungan Nomor: KM 14 Tabun 2006 Tentang Manajemen Dan Rekayasa Lalu Lintas Di Jalan. Jakarta: Kementrian Perhubungan..

PTV. AG. 2015. PTV. Vistro User Manual. Germany: PTV Group

Gati Rahayu, Sri Atmaja P. dan Ahmad Munawar. 2009. Analisis Arus Jenuh dan Panjang Antrian pada Simpang Bersinyal: Studi Kasus di Jalan Dr. Sutomo-Suryopranoto, Yogyakarta. Yogyakarta: Jurnal Ilmiah Semesta Teknika. Vol. 12, No.1: 99-108.

Rifai, A., Sulistyono, S. danSoetjipto, J.W.. 2014. Simulasi Analisis Dampak. Lalu Lintas Menggunakan PTV Vistro (Studi Kasus : Komplek Ruko Berjaya Batam), Prosiding FSTPT, Simposium Internasional FSTPT ke-17 di Universitas Jember, 24 Agustus 2014, Volume 2 Nomor 1, ISSN: 2356-0509. Jember: FSTPT Indonesia dan Jurusan Teknik Sipil Universitas Jember. Hal.1508-1518.

Sauri, S., Sulistyono, S. dan Hasanuddin, A.. 2014. Analisis Kinerja Simpang Menggunakan Perangkat Lunak. KAJI dan PTV Vistro (Studi Kasus: Simpang Bersinyal dan Tak Bersinyal Perkotaan Jember), Prosiding FSTPT, Simposium Internasional FSTPT ke-17 di Universitas Jember, 24 Agustus 2014, Volume 2 Nomor 1, ISSN: 2356-0509. Jember: FSTPT Indonesia dan Jurusan Teknik Sipil Univrsitas Jember. Hal.14981507.

Sulistyono, S., Iawan, J.F. dan Septiawan, D. 2015. Traffic Impact Analysis on The Development of Jember Icon Using PTV Vistro, Prosiding FSTPT, The 18th FSTPT Internasional Symposium di Universitas Lampung, 28 Agustus 2016, Lampung: FSTPT Indonesia dan Jurusan Teknik Sipil Universitas Lampung. Hal.876885.

Sulistyono, Sonya. 2016. Perbandingan Kinerja Simpang Menggunakan PTV Vistro Dan MKJI Pada Kawasan Perkotaan Lumajang. Jurnal. Simposium XIX FSTPT. Universitas Islam Indonesia. Yogyakarta. 